Old Dominion University ODU Digital Commons

Psychology Faculty Publications

Psychology

2015

\title{
Modeling Risk for Child Abuse and Harsh Parenting in Families with Depressed and Substance-Abusing Parents
}

\author{
Michelle L. Kelley \\ Old Dominion University \\ Hannah R. Lawrence \\ Robert J. Milletich \\ Old Dominion University \\ Brittany F. Hollis \\ Old Dominion University \\ James M. Henson \\ Old Dominion University
}

Follow this and additional works at: https://digitalcommons.odu.edu/psychology_fac_pubs

Part of the Psychology Commons

\section{Repository Citation}

Kelley, Michelle L.; Lawrence, Hannah R.; Milletich, Robert J.; Hollis, Brittany F.; and Henson, James M., "Modeling Risk for Child Abuse and Harsh Parenting in Families with Depressed and Substance-Abusing Parents" (2015). Psychology Faculty Publications. 41. https://digitalcommons.odu.edu/psychology_fac_pubs/41

\section{Original Publication Citation}

Kelley, M. L., Lawrence, H. R., Milletich, R. J., Hollis, B. F., \& Henson, J. M. (2015). Modeling risk for child abuse and harsh parenting in families with depressed and substance-abusing parents. Child Abuse \& Neglect, 43, 42-52. doi: 10.1016/j.chiabu.2015.01.017

This Article is brought to you for free and open access by the Psychology at ODU Digital Commons. It has been accepted for inclusion in Psychology Faculty Publications by an authorized administrator of ODU Digital Commons. For more information, please contact digitalcommons@odu.edu. 
Published in final edited form as:

Child Abuse Negl. 2015 May ; 43: 42-52. doi:10.1016/j.chiabu.2015.01.017.

\title{
Modeling Risk for Child Abuse and Harsh Parenting in Families with Depressed and Substance-abusing Parents
}

\author{
Michelle L. Kelley, \\ Old Dominion University \\ Hannah R. Lawrence, \\ University of Maine \\ Robert R. Milletich, \\ Old Dominion University \\ Brittany F. Hollis, and \\ Old Dominion University \\ James M. Henson \\ Old Dominion University
}

\begin{abstract}
Children with substance abusing parents are at considerable risk for child maltreatment. The current study applied an actor-partner interdependence model to examine how father only $(n=52)$ and dual couple $(\mathrm{n}=33)$ substance use disorder, as well as their depressive symptomology influenced parents' own (actor effects) and the partner's (partner effects) overreactivity in disciplinary interactions with their children, as well as their risk for child maltreatment. Parents completed the Center for Epidemiologic Studies Depression Scale (CES-D; Radloff, 1977), the overreactivity subscale from the Parenting Scale (Arnold, O'Leary, Wolff, \& Acker, 1993), and the Brief Child Abuse Potential Inventory (Ondersma, Chaffin, Mullins, \& LeBreton, 2005). Results of multigroup structural equation models revealed that a parent's own report of depressive symptoms predicted their risk for child maltreatment in both father SUD and dual SUD couples. Similarly, a parent's report of their own depressive symptoms predicted their overreactivity in disciplinary encounters both in father SUD and dual SUD couples. In all models, partners' depressive symptoms did not predict their partner's risk for child maltreatment or overreactivity. Findings underscore the importance of a parent's own levels of depressive symptoms in their risk for child maltreatment and for engaging in overreactivity during disciplinary episodes.
\end{abstract}

\footnotetext{
(C) 2015 Published by Elsevier Ltd.

Please address correspondence to: Michelle L. Kelley, Ph.D. Professor and Asst. Chair Department of Psychology Old Dominion University Norfolk, VA 23529-0267 1-757-683-4459 (work) 1-757-683-5087 (fax) mkelley@ odu.edu.

Publisher's Disclaimer: This is a PDF file of an unedited manuscript that has been accepted for publication. As a service to our customers we are providing this early version of the manuscript. The manuscript will undergo copyediting, typesetting, and review of the resulting proof before it is published in its final citable form. Please note that during the production process errors may be discovered which could affect the content, and all legal disclaimers that apply to the journal pertain.
} 


\section{Keywords}

substance use disorder; depression; child maltreatment

A Comparison between Father Only and Dual Substance-Abusing Parents Parental substance abuse is an unremitting problem that has deleterious effects on children in their homes. Among the most serious effects of parental substance use disorder (SUD) are overly punitive parenting and child maltreatment (see Staton-Tindall, Sprang, Clark, Walker, \& Craig, 2013 for a review). Identifying factors that lead to maladaptive parenting and child maltreatment is vital to developing more effective treatments that reduce risk for children in substance-abusing homes. One such factor, parental depression, has been shown to mediate the association between severity of substance use and paternal involvement with their children among drug-abusing men (Stover, Urdahl, \& Easton, 2012). Although much of the literature on parenting among parents with SUD has focused on single drug-abusing mothers (e.g., Hill, Lynne-Landsman, \& Boyce, 2012), with the exception of prescription drug abuse, men are more likely than women to abuse substances (SAMSHA, 2014). Furthermore, women with SUD often have partners that also misuse substances (e.g., Grella, Scott, \& Foss, 2005; Hser, Evans, \& Huang, 2005). In the case of two-parent families in which one or both partners have SUD, parents may impact their own, as well as their partners' parenting and risk for child maltreatment. For these reasons, we examined father only SUD versus dual parent SUD and depressive symptoms, two crucial determinants that have rarely been examined together, as related to each parents' reports of parental overreactivity and risk for child maltreatment.

\section{Parenting Behavior and Risk for Child Maltreatment among Parents with SUD}

Mothers with SUD exhibit less warmth and sensitivity and use harsher discipline with their children than mothers without SUD (see Gruber \& Taylor, 2006 for a review; Hien \& Honeyman, 2000; Pears, Capaldi, \& Owen, 2007). Children of opioid-using, alcohol-using, or dual substance-using mothers, for example, endorsed high levels of maternal rejection, psychological control, and inconsistent discipline on the Child's Report of Parenting Behavior Inventory (CRPBI; Slesnick, Feng, Brakenhoff, \& Brigham, 2014). Even more troubling, maternal SUD has been associated with an increased risk for child abuse and neglect (e.g., Grella, Hser, \& Huang, 2006; Gruber \& Taylor, 2006 for a review; Hien \& Honeyman, 2000).

Although an under-researched population (McMahon, Winkel, Suchman, \& Rounsaville, 2007), parenting of fathers with SUD also appears to have important influences on their children (e.g., Eiden, Molnar, Colder, Edwards, \& Leonard, 2009; Jacob, Krahn, \& Leonard, 1991; Leonard \& Eiden, 2007). Specifically, as compared to fathers without alcohol use disorder, alcohol-abusing fathers exhibit lower positive involvement, greater negative emotion (Eiden et al., 2009; Leonard \& Eiden, 2007), and less positive affect (Jacob et al., 1991) when interacting with their children. Importantly, in Edwards et al.'s (2011) study of alcohol-abusing mothers and non-substance-abusing mothers, both mothers and fathers 
exhibited overreactivity towards their children. Not surprisingly, harsh parenting among fathers with AUD is also associated with child anxiety (Eiden et al., 2009; Leonard \& Eiden, 2007), physical child abuse, and poorer parent-child relationships (Blackson et al., 1999).

\section{Dual SUD Couples versus Father SUD Families and Parenting}

Whether having dual SUD parents conveys greater risk for child abuse and overreactive disciplinary episodes than single parent SUD has received relatively little attention. Leonard and Eiden (2007) found that fathers in dual alcohol use disorder (AUD) couples and father only AUD couples had lower warmth and sensitivity in interactions with their children as compared to non-alcohol-abusing fathers. In contrast, non-AUD mothers with AUD partners' displayed less warmth, sensitivity, and had higher negative affect in interactions with their children as compared to mothers in which neither parent had AUD; however, no significant differences in parent-child interactions were found between mothers in dual AUD couples and mothers in non-substance-abusing control families. However, the nonsignificant finding between maternal parent-child interactions in dual AUD couples and mothers in non-substance-abusing families may reflect the small sample size for the dual AUD group. Mothers' lack of warmth and sensitivity did predict children's poor selfregulation, which in turn predicted children's externalizing behaviors, further emphasizing the impact maternal characteristics can have on child outcomes.

Dube et al. (2001) found that adults who retrospectively reported that their mother, father, or both parents were problem drinkers or alcoholic also had a 2- to 3-fold higher likelihood of having experienced adverse childhood experiences (ACEs; e.g., child physical abuse, sexual abuse, emotional neglect, mental illness, etc.). Those who resided with dual AUD parents also had the highest likelihood of ACEs, especially child physical abuse and sexual abuse (Walsh, MacMillan, \& Jamieson, 2003). Related to the findings of Walsh et al., Osborne and Berger (2009) found that three-year-olds were at a higher risk for poor behavioral outcomes when they had dual SUD parents versus a single SUD parent. In one of the few studies to examine associations between female and male substance-abusing caregivers, estimates between parenting and children's externalizing symptoms were stronger for families in which mothers had SUD and fathers did not; however, parent gender differences accounted for little variance in children's externalizing behavior (Stanger, Dumenci, Kamon, \& Burstein, 2004). In summary, dual parent AUD/SUD may contribute greater risk than single parent AUD/SUD (Dube et al., 2001; Osborne \& Berger, 2009; Walsh et al., 2003), especially when comparing paternal substance use to both maternal and paternal substance use (e.g., Christoffersen \& Soothill, 2003; Stanger et al., 2004). Given these findings, and that most studies have focused on parents with AUD, additional studies of single and dual parents with drug use disorders are needed.

\section{Harsh Parenting, Risk for Child Maltreatment, and Depressive Symptoms among Mothers and Fathers with SUD}

Although a number of mechanisms likely impact relationships between substance use, poor parenting, and child maltreatment, one factor that may underlie this association is parental depression. SUD and mood disorders often co-occur (Grant et al., 2004; Kessler et al., 2003; 
Luthar \& Sexton, 2007). Although the association between depression and drug use is likely bidirectional, drug or alcohol use can produce mood swings, irritability, or mood disorders especially when consumed in high doses (e.g., Kessler, 2004; see O'Brien et al., 2004 for a review; Schuckit et al., 2007), suggesting that SUD may provide one pathway to depression.

Researchers have found that depressed mothers are more critical and hostile with their children than non-depressed mothers (e.g., Conger, Patterson, \& Ge, 1995). Furthermore, depressive symptoms correlate with increased maternal aggressive behavior (Dubowitz et al., 2011) and child abuse and neglect (e.g., Burke, 2003; Dubowitz et al., 2011; Hien, Cohen, Caldeira, Flom, \& Wasserman, 2010; Sheppard, 1997). Moreover, depressed fathers experience greater conflict with their children than non-depressed fathers (Kane \& Garber, 2004) and fathers who screened positive for depression were more likely to report heavy corporal punishment (defined as a few times to every day or nearly every day in the previous month) with their young children than those without depression (Lee, Perron, Taylor, \& Guterman, 2011). Importantly, parents who are aggressive toward their partners and children reported higher depressive symptoms than partner-aggressive or child-aggressive only respondents (Tajima, 2004).

\section{Harsh Parenting, Child Maltreatment Risk, and Mental Health among non- Substance-abusing Partners}

Historically, research has focused on the parenting practices of SUD parents themselves (e.g., Lang, Pelham, Atkeson, \& Murphy, 1999), rather than the role of non-SUD partners. Although further research is needed, initial studies show that female spouses of male alcoholics report higher levels of overall psychological distress than the general population, as measured by a composite rating of anxiety, depression, aggression, and cognitive impairment (Tempier, Boyer, Lambert, Mosier, \& Duncan, 2006). In addition, researchers have found wives of alcoholics to have a higher risk of suicide (Manohar \& Kannappan, 2010) and greater somatic anxiety (Kodandaram, 1996) than wives of non-alcohol abusing partners. Furthermore, Manohar and Kannappan (2010) found that wives of men with alcohol use disorder reported their husbands to be more psychologically abusive as compared to wives whose husbands did not have SUD.

\section{Theoretical Explanations for the Link Between Parental SUD, Depression, and Overreactivity During Disciplinary Episodes and Risk for Child Maltreatment}

A number of processes have been proposed to explain interrelationships between parents and children (Erel \& Burman, 1995). In the present model, we tested both spillover and crossover effects. Spillover occurs when parents' experiences or affect (e.g., the parent domain) influence another domain (e.g., parent-child domain) (Almeida, Wethington, \& Chandler, 1999). In the case of parents with SUD, the interpersonal stress, frustration, and hopelessness associated with substance use may exacerbate negative affect and depressive symptoms, which then extends to overreactivity during disciplinary events and risk for child maltreatment. Crossover refers to the transfer of experience or influence from one person to 
another. During periods of high substance use, parents with SUD can be emotionally and physically unavailable to their children (e.g., McMahon et al., 2007). The non-substanceabusing parent may be preoccupied by their partners' substance abuse, experience role overload from compensating for their partners' family and parenting roles, and have difficulty maintaining a supportive dyadic and family environment (Miller, Smyth, \& Mudar, 1999). As might be expected, non-SUD women with male SUD partners have greater psychological distress (Tempier et al., 2006). Thus, even in families in which mothers do not have SUD, their depression symptoms may crossover, that is influence, their partners risk for detrimental effects on their partners' parenting practices.

By examining data from both parents, we were able to use an Actor-Partner Interdependence framework (see Kenny, Kashy, \& Cook, 2006 for a detailed discussion) to account for the dyadic nature of the data. Specifically, two sets of multigroup structural equation models were estimated to examine the effects of fathers' and mothers' depressive symptoms on their: 1) child abuse potential, and 2) parental overreactivity during disciplinary episodes. We had no evidence that actor or partner effects would differ as a function of parent gender; therefore, we hypothesized both actor and partner effects on mothers' and fathers' reports of depressive symptoms on child abuse potential and higher overreactivity during disciplinary episodes. Because previous research has not examined whether partners' depressive symptoms may have stronger effects on parenting risk for father only versus dual couple SUD, we conducted multigroup exploratory analyses to clarify this issue; however, no directional hypotheses were made.

\section{Method}

\section{Participants}

The sample consisted of 85 heterosexual couples in which the father only $(n=52)$ or both parents $(n=33)$ met Diagnostic and Statistical Manual (4th ed., text rev.; DSM-IV-TR; American Psychiatric Association, 2000) criteria for a drug and/or AUD. Families were recruited for a larger study examining the effects of parental treatment for SUD on their children at one of two outpatient treatment centers (one in western New York, one in southeastern Virginia). Data for the present study were obtained from pretreatment assessments.

Couples were married or in a stable relationship and had at least one child 18 years of age or younger ( $M=9.98$ years, $S D=4.64$ years). In the case of families with more than one child in the age range, parents reported on the child with the closest birthday to the initial screening. Families were excluded if (a) one or both parents did not meet DSM-IV-TR criteria for drug or alcohol abuse or both; (b) the child had cognitive, physical, or psychological limitations that would preclude interview, (c) the child did not reside with the parent full-time or have regular overnight visitation, or (d) any family member was not fluent in English. Couples who consented to participate were compensated \$60.00 (\$30.00 each) for their time.

Among the 52 couples in the present study in which only the father met DSM-IV criteria for SUD, 10 met criteria for an AUD, 8 met criteria for a drug disorder, and 34 met criteria for 
both an alcohol use and drug use disorder. To determine if the three father only SUD couples $(1=$ alcohol diagnosis only, $2=$ drug diagnosis only, $3=$ both alcohol and drug diagnoses) were significantly different on fathers' or mothers' reports of depressive symptoms, child abuse potential, and overreactivity, a series of one-way analysis of variances were conducted. Results demonstrated that mean scores of the father SUD only couples did not differ significantly on any of the six study variables ( $p$ s ranging from .094 to .951). Therefore, these groups were collapsed into a single group termed father SUD couples $(n=52)$. Family demographic characteristics are presented in Table 1.

\section{Overview of Measures and Procedure}

Parents were interviewed separately using the substance use modules of the Structured Clinical Interview for DSM-IV (SCID; First, Spitzer, Gibbon, \& Williams, 1996). The SCID was used to delineate parents' SUD and to identify participants who met one or more of the diagnostic exclusion criteria. Additionally, fathers and mothers independently and separately completed the following series of self-report questionnaires addressing depressive symptoms, potential for child abuse, and overreactivity during disciplinary episodes.

\section{Center for Epidemiologic Studies Depression Scale (CES-D; Radloff, 1977)-}

Parents completed the 20-item CES-D to assess for depressive symptomology. Items are rated from 0 (Rarely or none of the time [less than one day]) to 3 (Most or all of the time [5-7 days]) based on how frequently the individual experienced the symptom during the past week. Sample items include "I felt lonely" and "I could not get going." Item scores were summed to create a total score with higher scores reflecting more frequent symptomology. Researchers have found the CES-D to have very high internal consistency and adequate testretest reliability, as well as support for the construct validity (Radloff, 1977). A cut-off score of 16 is frequently used to identify possible clinical depression (Radloff, 1977; Radloff \& Locke, 2008). For those with no missing data, based on a cut-off score of 16, among father only SUD couples, $38.64 \%$ of fathers and $52.00 \%$ of mothers in the present sample were categorized as at risk for clinical depression. Among dual SUD couples, $43.33 \%$ of fathers and $63.33 \%$ of mothers in the present sample were categorized as at risk for clinical depression. Cronbach's alphas in the present study were .84 (father SUD couples) and .92 (dual SUD couples) for fathers' reports and .90 (father SUD couples) and .94 (dual SUD couples) for mothers' reports.

Brief Child Abuse Potential Inventory (BCAP; Ondersma et al., 2005)—The 24item BCAP was used to assess parental risk for physical abuse. Each parent completed the BCAP independently and in separate rooms. The BCAP is a brief version of the Child Abuse Potential Scale (CAP; Milner \& Gold, 1986). Sample items include, "I sometimes worry that my needs will not be met," "My family fights a lot," and "I am easily upset by my problems." Items are scored 1 (Agree) or 0 (Disagree). Items were reverse-scored as appropriate. Item scores were summed to create a total score; higher scores reflect greater risk for child abuse. The BCAP has established reliability (Blinn-Pike \& Mingus, 2000) and the BCAP risk scale correlates substantially with the risk scale derived from the CAP $(r=$. 96). For those with no missing data, based on a cut-off score of 9 (Ondersma et al., 2005), among father only SUD couples, $40.91 \%$ of fathers and $50.00 \%$ of mothers in the present 
sample were categorized as high risk for abuse. Among dual SUD couples, $30.00 \%$ of fathers and $61.29 \%$ of mothers in the present sample were categorized as high risk for abuse. Cronbach's alphas in the present study were .83 (father SUD couples) and .82 (dual SUD couples) for fathers' reports and .88 (father SUD couples) and .91 (dual SUD couples) for mothers' reports.

Parenting Scale (PS; Arnold, O'Leary, Wolff, \& Acker, 1993)—The 10-item Overreactivity subscale of the PS was used to assess parental overreactivity while disciplining their child. Each parent responded to scenarios on a 5-point Likert scale. Sample items are "When my child misbehaves" with responses ranging from 1 (I handle it without getting upset) to 5 (I get so frustrated or angry that my child can see that I am upset) and "When there is a problem with my child" with responses ranging from 1 (Things don't get out of hand) to 5 (Things build up and I do things I don't mean to do). Item scores were summed to create a total score with higher scores indicating greater reactivity. Evidence has been found for the reliability, internal consistency, and validity of the PS (Harvey, Danforth, Ulaszek, \& Eberhardt, 2001). The PS is correlated with observed parenting behavior and children's problem behavior (Arnold et al., 1993). In the present study, Cronbach's alphas were .71 (father SUD couples) and .74 (dual SUD couples) for fathers' reports and .75 (father SUD couples) and .88 (dual SUD couples) for mothers' reports.

\section{Results}

\section{Preliminary Analyses}

Data were first examined for missing values and outliers. Boxplots revealed no univariate outliers (i.e., outside the three interquartile range) on fathers' or mothers' depressive symptoms (assessed by the CES-D), child abuse potential (assessed by the BCAP), or overreactivity (assessed by the PS) among father SUD couples or dual SUD couples. Missing data ranged from 5.88\% on mothers' depressive symptoms to $12.94 \%$ on fathers' depressive symptoms, child abuse potential, and overreactivity. Little's missing completely at random (MCAR) test (1988) was not statistically significant $(p=.22)$, suggesting that the data were MCAR. Descriptive statistics for study variables are presented in Table 2 and Table 3.

We also examined whether children's ages were associated with mothers' and fathers' scores on risk for child abuse and parental overreactivity. Because the correlations between mothers' and fathers' scores and child age were not correlated, we did not control for child age.

\section{Model Testing}

Two sets of multigroup structural equation models were estimated to examine the effects of mothers' and fathers' depressive symptoms on their parental overreactivity and risk for child abuse. The grouping variable for the models was couple type $(0=$ father SUD couple, $1=$ dual SUD couple). An Actor-Partner Interdependence Model (APIM) (see Kenny et al., 2006) was used to account for the dyadic nature of the data. APIMs are useful for modeling statistically nonindependent data (e.g., couple data) to simultaneously examine the effects of 
each partner's behaviors on their own behavior as well as the other partner's behavior. The primary exogenous variables were fathers' and mothers' reports of depressive symptoms. The endogenous variables were fathers' and mothers' reports of child abuse potential in the first APIM and fathers' and mothers' reports of overreactivity in the second APIM.

Model testing proceeded as follows. First, configural models were estimated in which all parameters were freely estimated across the couple type. Next, actor effects (i.e., direct effects of fathers' [mothers'] depressive symptoms on his [her] own child abuse potential or overreactivity), partner effects (i.e., direct effects of fathers' [mothers'] depressive symptoms on his [her] partner's child abuse potential or overreactivity), the covariance among the exogenous variables, and the covariance among the disturbances were constrained to equality across parent gender and couple type. Chi-square difference tests were used to determine if compared to the configural models, the constrained models significantly increased model misfit. Other fit indices (e.g., root mean error of approximation [RMSEA], Tucker-Lewis index [TLI], and standardized root mean square residual [SRMR]) were used to assess the adequacy of model fit. In terms of normality of the study variables, skewness estimates ranged from -0.20 on mother's BCAP scores among dual SUD couples to 1.30 for father's BCAP scores among dual SUD couples; kurtosis estimates ranged from 0.03 on father's overreactivity scores among dual SUD couples to 2.16 on mother's overreactivity scores among dual SUD couples. As such, due to concerns for non-normality of residuals, all models were estimated using a robust maximum likelihood estimator (i.e., MLR) in Mplus 7.2 (Muthén \& Muthén, 1998-2014). Missing data were handled via the default full-information maximum likelihood procedure in Mplus.

Child abuse potential —In the configural model, all paths were freely estimated across couple type, which resulted in $d f=0$ (i.e., a just-identified model) and no fit indices were calculated. A chi-square difference test revealed that, compared to the configural model, constraining actor effects, partner effects, the covariance among the exogenous variables, and the covariance among the disturbances across parental gender and couple type did not significantly increase model misfit, $\Delta \chi^{2}(8, N=85)=7.17, p=.52$. Although the RMSEA and TLI fit indices indicated good model fit (i.e., RMSEA $=.000$, TLI $=1.00$ ), the SRMR fit index did not (SRMR = .12) (Hu \& Bentler, 1999).

Examination of the normalized residuals indicated a large value (normalized residual = -2.07) for the association between fathers' depressive symptoms and fathers' child abuse potential among dual SUD couples. Although a modification index (MI) suggested that freely estimating the direct effect of fathers' depressive symptoms on fathers' child abuse potential would improve fit $(\mathrm{MI}=4.54)$ in the dual SUD couples model, after accounting for the scaling correction factors, a chi-square difference test was not statistically significant, $\Delta \chi^{2}(1, N=85)=2.88, p=.09$. Therefore, the fully constrained model was retained as the final model. As can be seen in Figure 1, all actor effects were statistically significant, whereas, no partner effects were statistically significant.

Overreactivity-Similar to the previous model, the configural model was saturated and no fit indices were calculated. Likewise, compared to the configural model, a chi-square difference test revealed that constraining actor effects, partner effects, the covariance among 
the exogenous variables, and the covariance among the disturbances across parental gender and couple type did not significantly increase model misfit, $\Delta \chi^{2}(8, N=85)=4.38, p=.82$, RMSEA $=.00, \mathrm{TLI}=1.00$, and SRMR $=.08$ (Hu \& Bentler, 1999). In addition, no MIs indicated that the model could be significantly improved. The fitted model is displayed in Figure 2. All actor effects were statistically significant; no partner effects were statistically significant.

\section{Discussion}

Parental SUD is associated with overly punitive parenting and child maltreatment (see Staton-Tindall et al., 2013 for a review). Relative to our understanding of maternal SUD and depression and risk for child maltreatment, we know less about the impact of fathers' SUD and depressive symptoms on risk for child maltreatment and overreactivity during disciplinary encounters. Furthermore, whether partners' depressive symptoms have crossover effects on their partners' reports of risk for maltreatment and overreactivity during disciplinary situations has been the subject of little attention. Here we examined both spillover (i.e., actor) and crossover (i.e., partner) effects, that is, how mothers and fathers' depressive symptoms affect their own and their partners' parenting in two-parent families in which one or both partners met criteria for SUD. The importance of identifying variables that contribute to child maltreatment cannot be underestimated in this population which experiences high rates of Child Protective Services involvement. In fact, while we focused on risk for child abuse, in follow-up questions we asked partners separately whether there had either been a Child Protective Services case that involved the child in the study. Notably, 18 percent of mothers and 16 percent of fathers' reported there had been a previous CPS case now closed that involved the study child.

Results of multigroup structural equation models revealed partial support for the actorpartner interdependence model. Specifically, we found actor effects for mothers and fathers' depressive symptoms on risk for child maltreatment and overreactivity during disciplinary encounters such that each parents' depressive symptoms impacted their own parenting. That is, each parents' depressive symptoms contributed to their own reports of risk for child maltreatment and reactivity; however, there were no crossover effects.

With respect to the findings for mothers, our results support a long history of research showing a relationship between maternal depression symptomology and coercive maternal aggressive behaviors (e.g., Conger et al., 1995), as well as increased child abuse and neglect among mothers with (Hien et al., 2010) and without (e.g., Burke, 2003; Dubowitz et al., 2011; Sheppard, 1997) SUD. For one, mothers' depressive symptoms were significantly related to their own overreactivity in parenting, with increased depressive symptomology related to greater overreactivity. In addition, maternal depressive symptoms were also associated with increased child abuse potential, both in father-only and dual SUD families. Previous research has shown that women with AUD partners experience mental health problems (e.g., depression, anxiety) at a higher rate than women with non-AUD partners (Tempier et al., 2006) and that individuals with substance-abusing family members often feel isolated from external support (Easley \& Epstein, 1991). Importantly, however, the magnitude of the effects of maternal depressive symptoms on child abuse potential and 
overreactivity was stronger when both the mother and father had SUD than when only the father met criteria. This suggests that mothers' depressive symptoms may create greater risk for child maltreatment when both parents have SUD. In addition, mothers in dual SUD couples reported significantly more depressive symptoms than mothers with SUD partners. This finding is not surprising given the well-evidenced association between SUD and mood disorders (Grant et al., 2004; Kessler et al., 2003; Luthar \& Sexton, 2007) and previous research showing that relative to living with SUD partners, mothers' SUD is associated with higher negative affect (see Gruber \& Taylor, 2006 for a review; Hien \& Honeyman, 2000; Pears et al., 2007; Slesnick et al., 2014). Our findings are therefore consistent with literature suggesting that dual SUD may create greater risk for children in these homes (Dube et al., 2001; Osborne \& Berger, 2009; Walsh et al., 2003). Clinically, this highlights the importance of assessing depressive symptoms among mothers with SUD partners, as well as mothers in dual SUD couples when determining child risk of maltreatment.

Findings for fathers were identical to those of mothers with one exception. That is, fathers' depressive symptoms had moderate effects on risk for child maltreatment and small, but significant effects on disciplinary mistakes (i.e., overreactivity during disciplinary episodes). From a societal perspective, there is a tendency for fathers' substance abuse to be considered less critical for children's well-being than mothers' substance abuse. In part, the belief that men with SUD are less involved or critical to their children's lives may reflect less attention to fathers' substance abuse relative to mothers' substance abuse. In their meta-analytic study, Wilson and Durbin (2010) found paternal depression was associated with decreased positive and increased negative parenting behaviors. Moreover, the effects sizes between depression and parenting were comparable for mothers and fathers. Importantly, our results suggest that when fathers reside with their children, the pattern of associations between depressive symptoms and parenting may have similar risks for children. Furthermore, the strong effects of fathers' depressive symptoms and potential for child maltreatment risk among fathers with SUD clearly warrants the importance of integrated and comprehensive programs that address substance abuse, mental health, and parenting. Although these programs are often available for mothers (e.g., Milligan et al. 2010, 2011; Niccols et al., 2010, 2012) and have important benefits for women (e.g., Sword et al., 2009; Sword et al., 2013), with rare exceptions (see McMahon, 2013; see Stover et al., 2012, for a discussion), few such programs have been developed for fathers.

Importantly, our results support the actor-oriented effects posited by Kenney et al. (2006), in which a person's outcomes are a function of that person's characteristics only. That is, a parent's own report of depressive symptoms predicted their risk for child maltreatment and overreactivity during disciplinary episodes, rather than their partners. Results suggest the importance of assessing each partner's depression symptoms when evaluating a child's risk for maltreatment and overreactivity in families in which either the father only or both parents have SUD.

\section{Study Limitations}

Although the present findings add to the current body of literature by identifying depressive symptoms as a risk factor for child abuse and overreactivity in parents with SUD, several 
limitations exist suggesting that these results be interpreted with caution. First, many other factors may contribute to children's risk for child maltreatment in these homes. For instance, $53 \%$ of families meet Federal Poverty Guidelines. Not only may drug use, but financial strain may increase risk for child maltreatment or contribute to depressive symptoms among parents. Related to the first point, approximately $25 \%$ of parents reported they had entered substance abuse treatment before. Previous unsuccessful treatment attempts may discourage parents and again, potentially impact parents' behavior toward their children. It is important to note, that of the parents who had attempted previous substance abuse treatment, 40.3 percent of fathers but only 9.1 percent of mothers had received previous services. While it is difficult to speculate as to why this was the case, it is possible, women's substance use was less severe, that women had less ability to pay for substance abuse treatment, that their partners' were less supportive, or other concerns, such as coming to the attention of CPS services or childcare issues may have served to reduce women's treatment attempts. Also, depressive symptomology, child maltreatment, and parental overreactivity were all assessed using self-report. The accuracy of these self-reports may be further impacted by the sample's substance abuse patterns. It is also possible that common method variance may be impacting the results. Further replication using multiple methods to assess parenting behavior and depression may aid in clarifying the relationship between substance abuse, depressive symptoms and child risk in this population. Furthermore, our design does not allow for causal inference.

In addition to the concern of self-report, the majority of the present sample met criteria for both drug and alcohol use disorder. Although this is likely to reflect the tendency toward dual substance abuse in the general population, this is a notable limitation. Another study limitation is the lack of a mother only SUD group. This finding may reflect the fact that women with SUD are especially likely to partner with men with SUD (e.g., Gleiberman, Harburg, DiFranceisco, \& Schork, 1992; Sakai et al., 2004), that women's use of substances may be more interdependent with men's (Leonard \& Mudar, 2003), or that mothers with SUD may be more likely to be single parents than in a couple as their partners are unwilling to remain in the relationship. Future research may benefit from examining child age as related to child risk for maltreatment as well as examining potential differences in child outcomes based on whether the parent was engaged in either drug or alcohol abuse, and include a matched, non-substance-abusing control group.

\section{Clinical Implications}

These findings have importance implications for mental health providers who work with these families. With few exceptions (e.g., see Kelley, Klostermann, \& Henson, 2013), there are no treatment options for couples in which both parents have SUD. Given that many SUD men and women partner with those who also abuse substances, clearly, treating dual SUD is a critical issue. Furthermore, given that recent large-scale surveys have shown alcohol and drug use are similar for adolescent males and females (SAMHSA, 2005), it is possible that dual SUD couples will evolve into an even more pressing need in the near future. Although couples-based treatments for parents in which one or both partners have SUD are not widely available, these findings support the critical need for substance abuse treatment that integrates mental health assessment and therapy both for mothers and fathers with SUD, as 
well as non-SUD mothers with SUD partners. In particular, these results support the need for formal therapeutic work, as well widely-available less formal self-help programs and psychosocial education for women whose partners have SUD. In the case of non-SUD mothers, these programs may have benefits for mental health and potentially help mothers reduce depressive symptoms which may possibly have benefits for children in their homes.

\section{Conclusions}

Results of two multigroup structural equation models using an actor-partner interdependence framework revealed that mothers and fathers' own reports of depressive symptoms predicted their risk for child maltreatment and overreactivity in disciplinary episodes in both father SUD and dual SUD couples. In all models, partners' depressive symptoms did not predict their partner's risk for child maltreatment or overreactivity. Findings demonstrate the importance of a parent's own levels of depressive symptoms in their risk for child maltreatment and for overreactivity during disciplinary encounters. Furthermore, the pattern of associations between maternal depressive symptoms and risk for child maltreatment and overreactivity during disciplinary episodes and paternal depressive symptoms and parenting were largely the same, demonstrating the importance of fathers' negative affect and parenting risk among fathers with SUD who reside with children, and more globally, the importance of substance abuse treatment that incorporates elements of parenting for fathers.

\section{Acknowledgments}

This work was supported by the National Institute on Drug Abuse R01 DA024740 to the first author. We would like to thank the families that participated and members of the research and clinical team who assisted with work.

\section{References}

Almeida DM, Wethington E, Chandler AL. Daily transmission of tensions between marital dyads and parent-child dyads. Journal of Marriage and the Family. 1999; 61:49-61. doi:10.2307/353882.

American Psychiatric Association. Diagnostic and statistical manual of mental disorders (4th ed., text rev.). 2000 doi:10.1176/appi.books.9780890423349.

Arnold DS, O'Leary SG, Wolff LS, Acker MM. The Parenting Scale: A measure of dysfunctional parenting in discipline situations. Psychological Assessment. 1993; 5:137-144. doi: 10.1037/1040-3590.5.2.137.

Blackson TC, Butler T, Belsky J, Ammerman RT, Shaw DS, Tarter RE. Individual traits and family contexts predict sons' externalizing behavior and preliminary relative risk ratios for conduct disorder and substance use disorder outcomes. Drug Alcohol Dependence. 1999; 56:115-131. doi: 10.1016/S0376-8716(99)00030-7. [PubMed: 10482403]

Blinn-Pike L, Mingus S. The internal consistency of the Child Abuse Potential Inventory with adolescent mothers. Journal of Adolescence. 2000; 23:107-111. doi:10.1006/jado.1999.0297. [PubMed: 10700376]

Burke LL. The impact of maternal depression on familial relationships. International Review of Psychiatry. 2003; 15:243-255. doi:10.1080/0954026031000136866. [PubMed: 15276963]

Christoffersen M, Soothill K. The long-term consequences of parental alcohol abuse: A cohort study of children in Denmark. Journal of Substance Abuse Treatment. 2003; 25:107-116. Retrieved from http://www.journals.elsevier.com/journal-of-substance-abuse-treatment/. [PubMed: 14629993]

Conger RD, Patterson GR, Ge X. It takes two to replicate: A mediational model for the impact of parents' stress on adolescent adjustment. Child Development. 1995; 66:80-97. doi: 10.2307/1131192. [PubMed: 7497831] 
Dube SR, Anda RF, Felitti VJ, Croft JB, Edwards VJ, Giles WH. Growing up with parental alcohol abuse: Exposure to childhood abuse, neglect, and household dysfunction. Child Abuse \& Neglect. 2001; 25:1627-1640. doi:10.1016/S0145-2134(01)00293-9. [PubMed: 11814159]

Dubowitz H, Kim J, Black MM, Weisbart C, Semiatin J, Magder LS. Identifying children at high risk for a child maltreatment report. Child Abuse \& Neglect. 2011; 35:96-104. doi:10.1016/j.chiabu. 2010.09.003. [PubMed: 21376396]

Easley MJ, Epstein N. Coping with stress in a family with an alcoholic parent. Family Relations. 1991; 40:218-224. Retrieved from https://www.ncfr.org/fr.

Eiden RD, Molnar DS, Colder C, Edwards EP, Leonard KE. A conceptual model predicting internalizing problems in middle childhood among children of alcoholic and nonalcoholic fathers: The role of marital aggression. Journal of Studies on Alcohol and Drugs. 2009; 70:741-750. Retrieved from http://www.jsad.com. [PubMed: 19737499]

Erel O, Burman B. Interrelatedness of marital relations and parent-child relations: A meta-analytic review. Psychological Bulletin. 1995; 118:108-132. doi:10.1037/0033-2909.118.1.108. [PubMed: 7644602]

First, MB.; Spitzer, RL.; Gibbon, M.; Williams, JBW. Structured Clinical Interview for DSM-IV Axis I Disorders, Clinician Version (SCID-CV). American Psychiatric Press, Inc.; Washington, D.C.: 1996.

Gleiberman L, Harburg E, DiFranceisco W, Schork A. Familial transmission of alcohol use: V. Drinking patterns among spouses, Tecumseh, Michigan. Behavior Genetics. 1992; 22:63-79. doi: 10.1007/BF01066793. [PubMed: 1590731]

Grant BF, Stinson FS, Dawson DA, Chou SP, Dufour MC, Compton W, Kaplan K. Prevalence and cooccurrence of substance use disorders and independent mood and anxiety disorders: Results from the National Epidemiologic Survey on Alcohol and Related Conditions. Archives of General Psychiatry. 2004; 61:807-816. [PubMed: 15289279]

Grella CE, Hser Y, Huang Y. Mothers in substance abuse treatment: Differences in characteristics based on involvement with child welfare services. Child Abuse \& Neglect. 2006; 30:55-73. doi: 10.1016/j.chiabu.2005.07.005. [PubMed: 16406024]

Grella CE, Scott CK, Foss MA. Gender differences in long-term drug treatment outcomes in Chicago PETS. Journal of Substance Abuse Treatment. 2005; 28:S3-S12. doi: 10.1016/j.jsat.2004.08.008. [PubMed: 15797637]

Gruber KJ, Taylor M. A Family Perspective for Substance Abuse: Implications from the Literature. Journal of Social Work Practice in the Addictions. 2006; 6:1-29. doi:10.1300/J160v06n01_01.

Harvey E, Danforth JS, Ulaszek WR, Eberhardt TL. Validity of the parenting scale for parents of children with attention-deficit/hyperactivity disorder. Behaviour Research and Therapy. 2001; 39:731-743. doi:10.1016/S0005-7967(00)00052-8. [PubMed: 11400716]

Hien D, Cohen LR, Caldeira NA, Flom P, Wasserman G. Depression and anger as risk factors underlying the relationship between maternal substance involvement and child abuse potential. Child Abuse \& Neglect. 2010; 34:105-113. doi:10.1016/j.chiabu.2009.05.006. [PubMed: 20170960]

Hien D, Honeyman T. A closer look at the drug abuse-maternal aggression link. Journal of Interpersonal Violence. 2000; 15:503-522. doi:10.1177/088626000015005004.

Hill CV, Lynne-Landsman SD, Boyce C. Maternal and child health disparities: Considering the influence of fathers. American Journal of Public Health. 2012; 102:S164-S165. doi:10.2105/ AJPH.2012.300792. [PubMed: 22497199]

Hser YI, Evans E, Huang YC. Treatment outcomes among women and men methamphetamine abusers in California. Journal of Substance Abuse Treatment. 2005; 28:77-85. Retrieved from http:// www.journals.elsevier.com/journal-of-substance-abuse-treatment/. [PubMed: 15723735]

Hu LT, Bentler PM. Cutoff criteria for fit indexes in covariance structure analysis: Conventional criteria versus new alternatives. Structural Equation Modeling. 1999; 6:1-55. doi: 10.1080/10705519909540118.

Jacob T, Krahn GL, Leonard K. Parent-child interactions in families with alcoholic fathers. Journal of Consulting and Clinical Psychology. 1991; 59:176-181. doi:10.1037/0022-006X.59.1.176. [PubMed: 2002135] 
Kane P, Garber J. The relations among depression in fathers, children's psychopathology, and fatherchild conflict: A meta-analysis. Clinical Psychology Review. 2004; 24:339-360. doi:10.1016/j.cpr. 2004.03.004. [PubMed: 15245835]

Kelley, ML.; Klostermann, K.; Henson, JM. Behavioral couples therapy for substance-abusing parents.. In: Suchman, NE.; Pajulo, M.; Mayes, LC., editors. Parenting and substance abuse: Developmental approaches to intervention. Oxford University Press; New York, NY, US: 2013. p. 469-486.

Kenny, DA.; Kashy, DA.; Cook, WL. Dyadic data analysis. Guilford Press; New York, NY, US: 2006.

Kessler RC. Impact of substance abuse on the diagnosis, course, and treatment of mood disorders: The epidemiology of dual diagnosis. Biological Psychiatry. 2004; 56:730-737. doi:10.1016/j.biopsych. 2004.06.034. [PubMed: 15556117]

Kessler RC, Barker PR, Colpe LJ, Epstein JF, Gfroerer JC, Hiripi E, Zaslavsky AM. Screening for serious mental illness in the general population. Archives of General Psychiatry. 2003; 60:184189. doi:10.1001/archpsyc.60.2.184. [PubMed: 12578436]

Kodandaram PP. A study of personality of alcohol dependent individuals and their spouses. Journal of Personality and Clinical Studies. 1996; 12:17-22. Retrieved from http://dds.crl.edu/ CRLdelivery.asp?tid=5671.

Lang AR, Pelham WE, Atkeson BM, Murphy DA. Effects of alcohol intoxication on parenting behavior in interactions with child confederates exhibiting normal or deviant behaviors. Journal of Abnormal Child Psychology. 1999; 27:177-189. doi:10.1023/A:1021996122095. [PubMed: 10438184]

Lee SJ, Perron BE, Taylor CA, Guterman NB. Paternal psychosocial characteristics and corporal punishment of their 3-year-old children. Journal of Interpersonal Violence. 2011; 26:71-87. doi: 10.1177/0886260510362888. [PubMed: 20522884]

Leonard KE, Eiden RD. Marital and family processes in the context of alcohol use and alcohol disorders. Annual Review of Clinical Psychology. 2007; 3:285-310. doi:10.1146/annurev.clinpsy. 3.022806.091424.

Leonard KE, Mudar P. Peer and partner drinking and the transition to marriage: A longitudinal examination of selection and influence processes. Psychology of Addictive Behaviors. 2003; 17:115-125. doi:10.1037/0893-164X.17.2.115. [PubMed: 12814275]

Luthar SS, Sexton CC. Maternal drug abuse versus maternal depression: Vulnerability and resilience among school-age and adolescent offspring. Development and Psychopathology. 2007; 19:205225. doi:10.1017/S0954579407070113. [PubMed: 17241491]

Manohar PS, Kannappan RR. Domestic violence and suicidal risk in the wives of alcoholics and nonalcoholics. Journal of the Indian Academy of Applied Psychology. 2010; 36:334-338. Retrieved from http://www.jiaap.org.

McMahon, TJ. Fathers' Too: Building parent interventions for substance-abusing men.. In: Suchman, NE.; Pajulo, M.; Mayes, LE., editors. Parenting and substance abuse: Developmental approaches to intervention. Oxford University Press; New York: 2013. p. 447-468.

McMahon TJ, Winkel JD, Suchman NE, Rounsaville BJ. Drug-abusing fathers: Patterns of pair bonding, reproduction, and paternal involvement. Journal of Substance Abuse Treatment. 2007; 33:295-302. doi:10.1016/j.jsat.2006.12.010. [PubMed: 17399935]

Miller BA, Smyth NJ, Mudar PJ. Mothers' alcohol and other drug problems and their punitiveness toward their children. Journal of Studies on Alcohol and Drugs. 1999; 60:632-642. Retrieved from http://www.jsad.com.

Milligan K, Niccols A, Sword W, Thabane L, Henderson J, Smith A, Liu J. Maternal substance use and integrated treatment programs for women with substance abuse issues and their children: A meta-analysis. Substance Abuse Treatment, Prevention, and Policy. 2010; 5. doi: 10.1186/1747-597X-5-21.

Milner JS, Gold RG. Screening spouse abusers for child abuse potential. Journal of Clinical Psychology. 1986; 42:169-172. doi:10.1002/1097-4679(198601)42:1\&lt; 169::AIDJCLP2270420129\&gt;3.0.CO;2-2. [PubMed: 3950003]

Muthén, LK.; Muthén, BO. Mplus User’s Guide. Seventh Edition.. Muthén \& Muthén; Los Angeles, CA: 1998-2014. 
Niccols A, Milligan K, Sword W, Thabane L, Henderson J, Smith A, Jack S. Maternal mental health and integrated programs for mothers with substance abuse issues. Psychology of Addictive Behaviors. 2010; 24:466-474. Retrieved from http://www.apa.org/pubs/journals/adb/. [PubMed: 20853932]

O'Brien CP, Charney DS, Lewis L, Cornish JW, Post RM, Woody GE, Weisner C. Priority actions to improve the care of persons with co-occurring substance abuse and other mental disorders: A call to action. Biological Psychiatry. 2004; 56:703-713. doi:10.1016/j.biopsych.2004.10.002. [PubMed: 15556110]

Ondersma SJ, Chaffin MJ, Mullins SM, LeBreton JM. A brief form of the Child Abuse Potential Inventory: Development and validation. Journal of Clinical Child and Adolescent Psychology. 2005; 34:301-311. doi:10.1207/s15374424jccp3402_9. [PubMed: 15901230]

Osborne C, Berger LM. Parental substance abuse and child well-being: A consideration of parents' gender and coresidence. Journal of Family Issues. 2009; 30:341-370. doi: 10.1177/0192513X08326225.

Pears K, Capaldi DM, Owen LD. Substance use risk across three generations: The roles of parent discipline practices and inhibitory control. Psychology of Addictive Behaviors. 2007; 21:373-386. doi:10.1037/0893-164X.21.3.373. [PubMed: 17874888]

Pearson MR, D'Lima G, Kelley ML. Maternal and paternal alcohol abuse and alcohol-related outcomes among college students. Substance Use and Misuse. 2012; 47:708-717. Retrieved from http://informahealthcare.com/loi/sum/. [PubMed: 22404170]

Radloff LS. The CES-D Scale: A self-report depression scale for research in the general population. Applied Psychological Measurement. 1977; 1:385-401. doi:10.1177/014662167700100306.

Radloff, LS.; Locke, BZ. Center for Epidemiologic Studies Depression Scale (CES D).. In: Rush, AJ.; First, MB.; Blacker, D., editors. Handbook of Psychiatric Measures. American Psychiatric Publishing; Arlington, VA: 2008. p. 506-508.

Sakai JT, Stallings MC, Mikulich-Gilbertson SK, Corley RP, Young SE, Hopfer CJ, Crowley TJ. Mate similarity for substance dependence and antisocial personality disorder symptoms among parents of patients and controls. Drug and Alcohol Dependence. 2004; 75:165-175. doi:10.1016/ j.drugalcdep.2004.01.015. [PubMed: 15276222]

Schuckit MA, Smith TL, Danko GP, Pierson J, Trim R, Nurnberger JI, Hesselbrock V. A comparison of factors associated with substance-induced versus independent depressions. Journal of Studies on Alcohol and Drugs. 2007; 68:805-812. Retrieved from http://www.jsad.com. [PubMed: 17960298]

Sheppard M. Double jeopardy: The link between child abuse and maternal depression in child and family social work. Child \& Family Social Work. 1997; 2:91-107. doi:10.1046/j. 1365-2206.1997.00047.x.

Slesnick N, Feng X, Brakenhoff B, Brigham GS. Parenting under the influence: The effects of opioids, alcohol and cocaine on mother-child interaction. Addictive Behaviors. 2014; 39:897-900. doi: 10.1016/j.addbeh.2014.02.003. [PubMed: 24589871]

Stanger C, Dumenci L, Kamon J, Burstein M. Parenting and children's externalizing problems in substance-abusing families. Journal of Clinical Child and Adolescent Psychology. 2004; 33:590600. doi:10.1207/s15374424jccp3303_16. [PubMed: 15271616]

Staton-Tindall M, Sprang G, Clark J, Walker R, Craig CD. Caregiver substance use and child outcomes: A systematic review. Journal of Social Work Practice in the Addictions. 2013; 13:6-31. doi:10.1080/1533256X.2013.752272.

Stover C, Urdahl A, Easton C. Depression as a mediator of the association between substance abuse and negative parenting of fathers. The American Journal of Drug and Alcohol Abuse. 2012; 38:344-349. doi:10.3109/00952990.2011.649221. [PubMed: 22243417]

Substance Abuse and Mental Health Services Administration (SAMHSA). Results From the 2005 National Survey on Drug Use and Health: National Findings. SAMHSA, Office of Applied Studies; Rockville, MD: 2006. NSDUH Series H-30, DHHS Pub. No. SMA 06-4194

Sword W, Jack S, Niccols A, Milligan K, Henderson J, Thabane L. Integrated programs for women with substance use issues and their children: A qualitative meta-synthesis of processes and outcomes. Harm Reduction Journal. 2009; 6 doi:10.1186/1477-7517-6-32. 
Sword W, Niccols A, Yousefi-Nooraie R, Dobbins M, Lipman E, Smith P. Partnerships among Canadian agencies serving women with substance abuse issues and their children. International Journal of Mental Health and Addiction. 2013; 11:344-357. Retrieved from http:// www.springer.com/public+health/journal/11469. [PubMed: 23710160]

Tajima EA. Correlates of the co-occurrence of wife abuse and child abuse among a representative sample. Journal of Family Violence. 2004; 19:399-410. Retrieved from http://www.springer.com/ medicine/journal/10896.

Tempier R, Boyer R, Lambert J, Mosier K, Duncan C. Psychological distress among female spouses of male at-risk drinkers. Alcohol. 2006; 40:41-49. doi:10.1016/j.alcohol.2006.09.032. [PubMed: 17157719]

Walsh C, MacMillan HL, Jamieson E. The relationship between parental substance abuse and child maltreatment: Findings from the Ontario Health Supplement. Child Abuse \& Neglect. 2003; 27:1409-1425. doi:10.1016/j.chiabu.2003.07.002. [PubMed: 14644058]

Wilson S, Durbin CE. Effects of paternal depression on fathers' parenting behaviors: A meta-analytic review. Clinical Psychology Review. 2010; 30:167-180. doi: 10.1016/j.cpr.2009.10.007. [PubMed: 19926376] 

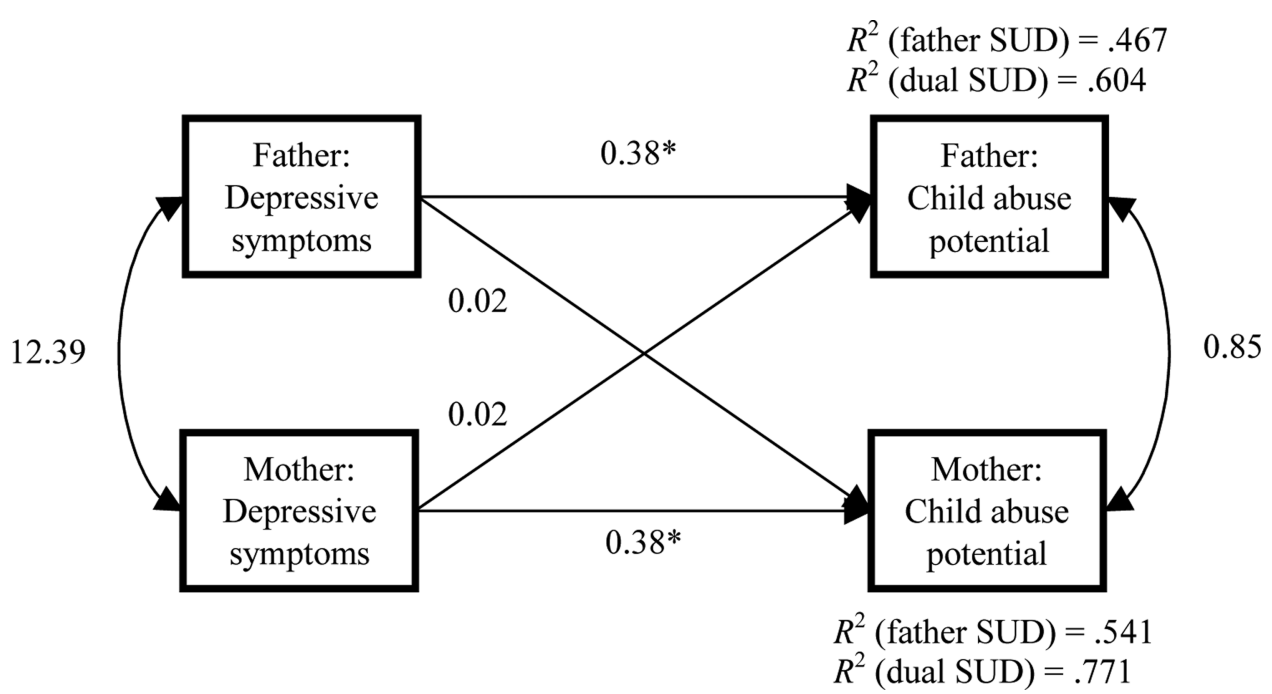

Figure 1.

Fitted multigroup model predicting fathers' and mothers' child abuse potential. Numbers are unstandardized parameter estimates. Numbers are unstandardized parameter estimates. All direct effects are constrained to equality across couple type. ${ }^{*} p<.001$. 

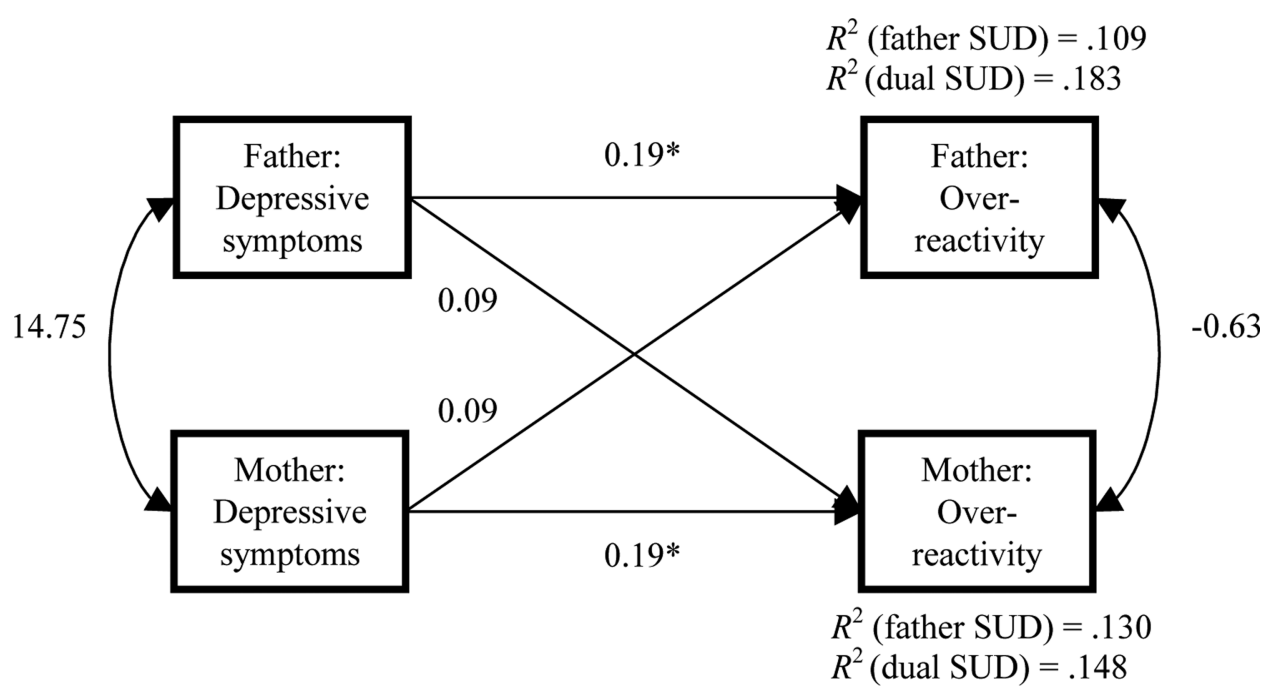

Figure 2.

Fitted multigroup model predicting fathers' and mothers' overreactivity. Numbers are unstandardized parameter estimates. All direct effects are constrained to equality across couple type. ${ }^{*} p<.001$. 
Table 1

Characteristics of Families in which the Fathers Met SUD of Both Partners Met DSM-IV-TR Criteria for SUD

\begin{tabular}{|c|c|c|c|c|}
\hline \multirow{2}{*}{$\begin{array}{l}\text { Characteristic } \\
\text { Father: }\end{array}$} & \multicolumn{2}{|c|}{ Fathers SUD $(n=52)$} & \multicolumn{2}{|c|}{ Dual SUD $(n=33)$} \\
\hline & $M$ & $S D$ & $M$ & $S D$ \\
\hline Age (in years) & 39.75 & 8.92 & 31.15 & 6.83 \\
\hline Education (in years) & 12.29 & 2.44 & 12.61 & 2.55 \\
\hline Ethnicity & $n$ & $\%$ & $n$ & $\%$ \\
\hline White & 32 & 61.54 & 23 & 69.70 \\
\hline African-American & 12 & 23.07 & 7 & 21.21 \\
\hline Hispanic & 4 & 7.69 & 2 & 6.06 \\
\hline Other & 2 & 3.85 & 1 & 3.03 \\
\hline Missing & 2 & 3.85 & 0 & 0.00 \\
\hline \multicolumn{5}{|l|}{ Employment status } \\
\hline Not employed & 15 & 28.85 & 13 & 39.39 \\
\hline Part-time & 8 & 15.38 & 2 & 6.06 \\
\hline Full-time & 27 & 51.92 & 18 & 54.54 \\
\hline Missing & 2 & 3.85 & 0 & 0.00 \\
\hline Mother: & $M$ & $S D$ & $M$ & $S D$ \\
\hline Age (in years) & 38.39 & 8.99 & 36.35 & 7.07 \\
\hline Education (in years) & 13.73 & 2.31 & 12.55 & 2.35 \\
\hline Ethnicity & $n$ & $\%$ & $n$ & $\%$ \\
\hline White & 39 & 75.00 & 26 & 78.79 \\
\hline African-American & 8 & 15.38 & 5 & 15.15 \\
\hline Hispanic & 3 & 5.77 & 2 & 6.06 \\
\hline Other & 1 & 1.92 & 0 & 0.00 \\
\hline Missing & 1 & 1.92 & 0 & 0.00 \\
\hline \multicolumn{5}{|l|}{ Employment status } \\
\hline Not employed & 23 & 44.23 & 19 & 57.58 \\
\hline Part-time & 7 & 13.46 & 8 & 24.24 \\
\hline Full-time & 19 & 36.54 & 6 & 18.18 \\
\hline Missing & 3 & 5.77 & 0 & 0.00 \\
\hline Couple: & $M$ & $S D$ & $M$ & $S D$ \\
\hline Years cohabitating & 9.03 & 7.66 & 8.67 & 6.33 \\
\hline
\end{tabular}

Child Abuse Negl. Author manuscript; available in PMC 2016 May 01. 


\section{로을}

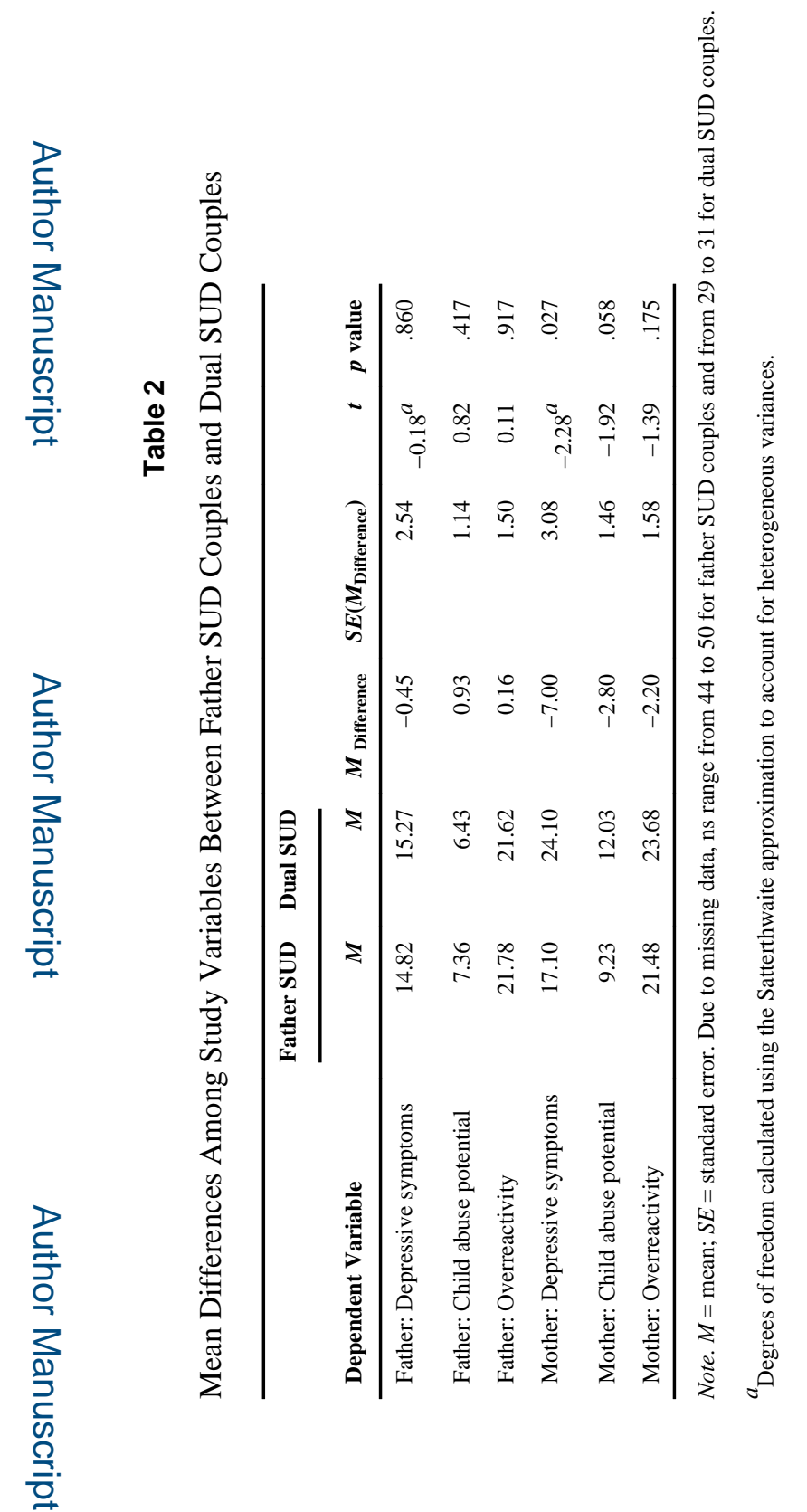

Child Abuse Negl. Author manuscript; available in PMC 2016 May 01. 


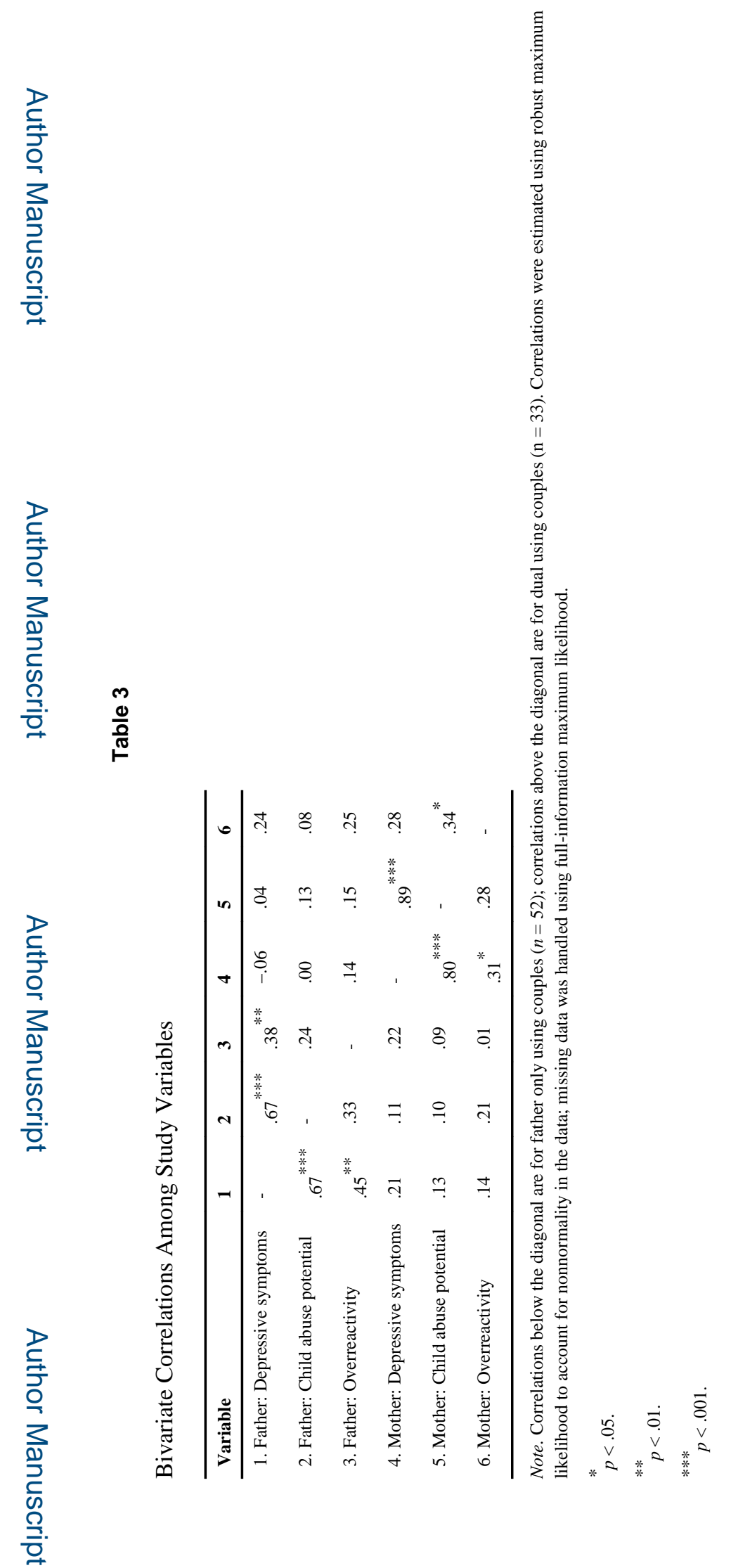

Child Abuse Negl. Author manuscript; available in PMC 2016 May 01. 